\title{
In Vitro Antioxidant Profile of Methanol Leaf Extract of Securidacalongepedunculata
}

\author{
${ }^{1}$ Abonyi O., ${ }^{1}$ Uzoegwu P.N., ${ }^{1}$ Ani C.C., ${ }^{1}$ Uroko R. I., ${ }^{1}$ Ezugwu A. L., ${ }^{1}$ Onyemuche, T. N., \\ ${ }^{2}$ Igwe, C.N. and Anigbogu J.U. \\ ${ }^{1}$ Department of Biochemistry, University of Nigeria, Nsukka, Nigeria \\ ${ }^{2}$ Department of pure and industrial chemistry, University of Nigeria, Nsuukka \\ ${ }^{3}$ Department of Biochemistry, Tansian University Umunya, AnambraState, Nigeria.
}

\begin{abstract}
The serious problem associated with the use of plants parts for medicinal purposes is the paucity of information on the phytochemistry, pharmacology, antioxidant contents and toxicity of most of the medicinal plants. The aim of this study is to evaluate the antioxidant property of the leaves of $S$. longepedunculata with a view to elucidating its antioxidant potential. The potent secondary metabolites in the leaves ofSecuridacalongepedunculata, were extracted and the antioxidant potential, evaluated using in vitro methods. Results showed that the methanol extract scavenged 1, 1- diphenyl- 2- picrylhydrazyl radical $(D P P H)$ in a concentration dependent manner with a correlation coefficient $\left(R^{2}\right)$ of 0.976 , indicating antioxidant activity with effective concentration that inhibits 50 percent of the radicals $\left(E C_{50}\right)$ of $90.02 \pm 0.2 \mu \mathrm{g} / \mathrm{ml}$ compared to ascorbic acid standard $\left(E C_{50}\right.$ of $98.01 \pm 0.2 \mu \mathrm{g} / \mathrm{ml})$. Superoxide radical scavenging activity was concentration dependent with an $E C_{50}$ of $350.11 \pm 0.42 \mu \mathrm{g} / \mathrm{ml}$ compared with ascorbic acid standard with $E C_{50}$ of $812.97 \pm 0.97 \mu \mathrm{g} / \mathrm{ml}$. The extract, also showed hydroxyl radical scavenging activity with an $E C_{50}$ of $83.74 \pm 0.02 \mu \mathrm{g} / \mathrm{ml}$ compared to $\alpha$ - tocopherol standard with $E C_{50}$ of $54.16 \pm 0.01 \mu \mathrm{g} / \mathrm{ml}$. There was an inverse correlation between the percentage inhibition and concentration with $R^{2}$ of -0.958. The methanol extract, also scavenged nitric oxide radical in a concentration dependent manner with $500 \mu \mathrm{g} / \mathrm{ml}$ being more effective than $500 \mu \mathrm{g} / \mathrm{ml}$ of ascorbic acid standard. Comparison of the anti-radical power (ARP) of DPPH (0.011), superoxide radical (0.003) and hydroxyl radical (0.012) of the extract revealed that the ARP of hydroxyl radical was most efficacious. The antioxidant vitamin contents of the extract showed that vitamin $C$ was significantly high ( $p<0.05),(4.62 \pm 0.14 \mathrm{mg} / 100 \mathrm{~g})$ when compared to vitamin $A$ $(0.902 \pm 0.05 \mu \mathrm{g} / \mathrm{g})$ and vitamin $E(1.474 \pm 0.01 \mathrm{mg} / 100 \mathrm{~g})$. This result suggests a moderate antioxidant activity which is healthy for a biological system to reduce the deleterious effects associated with excessive free radical generation.
\end{abstract}

Keywords:Phytochemistry, pharmacology, antioxidant contents and toxicity

\section{Introduction}

Antioxidants are substances that, when present in low concentrations, compared to that of an oxidizable substrate, significantly delay or prevent oxidation of the substrate (Halliwell and Gutteridge, 1989). Two classes of antioxidants are known. They include; the low molecular weight compounds such as vitamins $\mathrm{E}$ and $\mathrm{C}$, beta-carotene, glutathione, uric acid and bilirubin, proteins such asalbumin, transferrin, caeruloplasmin, ferritin, superoxidedismutase, glutathioneperoxidase and catalase (Psotovaet al., 2001). Typical phenolics that possess antioxidant activity have been characterized as phenolic acid and flavonoids (Kahkonenet al., 1999). The increasing awareness by consumers to issues regarding food additive safety, results in an enhanced effort in finding alternative additives and preservatives from natural and probably safer sources. Synthetic antioxidants are disadvantageous due to their side effectsinvivo(Balasundramet al., 2006). In this regard, food manufacturers have been encouraged to use natural antioxidants instead of synthetic 
compounds to maintain the nutritional values of their products. For instance, commercial antioxidants such as butylatedhydroxytoluene (BHT) and butylatedhydroxyanisole (BHA) can be replaced by plant extracts particularly polyphenols (Balasundramet al., 2006). Antioxidants usually prevent food oxidation, normally initiated by free radicals formed during the food's exposure to environmental factors such as air, light and temperature (Hraset al., 2000). Reactive oxygen species (ROS), which consist of free radicals such as hydroxyl radical $(\mathrm{OH})$, superoxide radical $\left(\mathrm{O}_{2}^{-}\right)$, Nitric oxide $\left(\mathrm{NO}^{-}\right)$, peroxyl $\left(\mathrm{RO}_{2}^{-}\right)$, lipid peroxyl $\left(\mathrm{LOO}^{-}\right)$radicals and non-free radical species such as hydrogen peroxide $\left(\mathrm{H}_{2} \mathrm{O}_{2}\right)$, singlet oxygen $\left(\mathrm{O}_{2}{ }^{-1}\right)$, ozone $\left(\mathrm{O}_{3}\right)$ and lipid peroxide $(\mathrm{LOOH})$, are different forms of activated oxygen (Halliwellet al., 1999; Yildrinet al., 2000; Gulcinet al., 2002). ROS are produced by all aerobic organisms and can easily react with proteins, lipids, lipoproteins and DNA, leading to an imbalance between the systemic manifestation of reactive oxygen species and a biological system's ability to readily repair the resulting damage (Halliwell, 2007). During times of environmental stress, systemic ROS levels can increase dramatically. Cumulatively, ROS could lead to many pathophysiological disorders such as arthritis, diabetes, inflammation, cancer and genotoxicity (Kourounakiset al., 1999; Gulcin and Oktay, 2002). Generation of free radicals during metabolism, givesrise to oxidative stresswhich could play a role in heart diseases, neurodegenerative diseases, cancer and in aging process (Astley, 2003). Antioxidants oppose these effects, thus lowering the risk of diseases (Atoui, 2005).SecuridacalongepedunculataLinn belonging to the family of polygalaceae, is a spiny semi-deciduous shrub that grows to about $12 \mathrm{~m}$ tall (Owoyeleet al., 2006). Eaten as vegetable, S. longepedunculata was reported to have analgesic, anti-inflammatory and hypoglycemic potentials (Ajiboyeet al., 2006), and is highly efficacious in treating malaria and rheumatism (Gill, 1992). It is also used in bacterial chemotherapy (Akinniyiet al., 1996; Mohammed et al., 2012). The plant is also used in the treatment of cough, headache, constipation, wound, sore throat and gout (Ojewale, 2008). Its anti-snake venom potential has also been reported (Wannaget al., 2005). Some secondary metabolite contents such as alkaloids and flavonoids and related compounds such as methyl salicylate has been reported (Iddagoda and Thamara, 2003; Abdullahi and Lawal, (2010).

\section{Materials and Methods \\ Collection of plant sample and Extraction of Securidacalongepedunculata Constituents}

The plant was harvested in a natural habitat at Nsukka, Enugu State Nigeria and identified by Alfred Ozioko of the Bioresources Diversity and Conservative Programme (BDCP) Nsukka. After shade drying, one hundred and fourteen $(114 \mathrm{~g})$ of the leaves were weighed after pulverizing, soaked with $80 \%$ methanol for $24 \mathrm{hrs}$ and filtered with Whatman filter paper no 1 . The filtrate was concentrated using rotary evaporator, and the solid extract stored in freezer at $4^{\circ} \mathrm{C}$ till used.

\section{Chemicals}

All chemicals used in this study were of analytical grade and products of Sigma Aldrich, (USA), British Drug House (BDH) (England), Burgoyne, (India), Harpkin and Williams, (England), Qualikems (India), Fluka (Germany), May and Baker, (England)

\section{Quantitative 1,1-diphenyl-2-picrylhydrazyl(DPPH:) Radical Scavenging Assay}

The scavenging activity on DPPH freeradical by the extract was tested using the method of Gyamfi, et al., (1999) with the following modifications. One milliliter (1 $\mathrm{ml})$ of the extract at different concentrations $(1.25-160 \mu \mathrm{g} / \mathrm{ml})$ was added followed by addition of $0.5 \mathrm{ml}$ of $0.076 \mathrm{mMDPPH}$. The solution was made up to $2 \mathrm{ml}$ by $80 \%$ methanoland the solution was 
allowed to stand at room temperature in the dark for $30 \mathrm{~min}$. The negative control was 0.076 $\mathrm{mM}$ DPPH in methanol. L-ascorbic acid was used as the positive control. Thereafter, the absorbance of the assay mixtures was read using a JENWAY 6405 UV/VIS spectrophotometer (Beckman/Instruments, Inc., Huston Texas) at $517 \mathrm{~nm}$ using. DPPH radical scavenging activity was calculated using the equation;

$\%$ scavenging activity $=100-\left(\frac{\text { Abs of Sample }}{\text { Abs of Control }} \times 100\right)$

Abs $=$ absorbance

The effective concentration at $50 \%$ inhibition $\left(\mathrm{EC}_{50}\right.$ value was calculated using a plot of $\%$ inhibition against different concentrations of the extract and it represented the concentration of the sample leading to $50 \%$ reduction in the initial DPPH concentration. Triplicate values were taken.

\section{Hydroxyl Radical (OH) Scavenging Assay}

The 2-deoxy ribose assay was determined using the method ofHalliwellet al., (1987). Each reaction mixture contained the following final concentrations of reagents in a final volume of $1 \mathrm{ml}$ : 2-deoxyribose $(2.5 \mu \mathrm{M})$, Potassium phosphate buffer $\left(20 \mathrm{mM} \mathrm{pH} \mathrm{7.4),} \mathrm{FeCl}_{3}\right.$ $(100 \mu \mathrm{M})$, EDTA $(104 \mu \mathrm{M}), \mathrm{H}_{2} \mathrm{O}_{2}(1 \mathrm{mM})$, and L-ascorbic acid $(100 \mu \mathrm{M})$. Solutions of $\mathrm{FeCl}_{3}$ and L-ascorbic acid were prepared immediately before use in distilled water. The mixtures were incubated for $1 \mathrm{hr}$ at $37^{\circ} \mathrm{C}$, followed by addition of $1 \mathrm{ml}$ of $1 \%(\mathrm{w} / \mathrm{v})$ thiobarbituric acid (TBA) in $0.05 \mathrm{M} \mathrm{NaOH}$ and $1 \mathrm{ml}$ of $2.8 \%$ trichloroaceticacid(TCA). The resulting mixtures were heated for 15 minutes at $100{ }^{\circ} \mathrm{C}$. After cooling on ice, absorbance was read at $532 \mathrm{~nm}$. Inhibition of 2-deoxyribose degradation expressed in percentage, was calculated using the following equation:

$$
\% \text { inhibition }=\frac{\mathrm{Ao}-\mathrm{As}}{\mathrm{Ao}} \times 100
$$

$\mathrm{A}_{\mathrm{o}}=$ absorbance of the control

As = absorbance of the test sample

The $\mathrm{IC}_{50}$ value was estimated using a plot of \% inhibition against different concentrations of the extract which represented the concentration of the sample leading to $50 \%$ inhibition of degradation of 2-deoxy ribose. Triplicate values were taken.

\section{Superoxide Radical Scavenging Assay}

Superoxide radical scavenging assay was performed according to the methods of Beauchamp and Fridovich, (1971) and Martinez et al. (2001). This was based on the capacity of the extract to inhibit the photochemical reduction of nitro blue tetrazolum (NBT). Briefly, each $3.0 \mathrm{ml}$ reaction mixture contained $0.05 \mathrm{M}$ Phosphate-buffered saline (PBS) (pH 7.8), 13 $\mathrm{mM}$ methionine, $2 \mu \mathrm{M}$ riboflavin, $100 \mu \mathrm{M}$ EDTA, NBT $(75 \mu \mathrm{M})$ and $1.0 \mathrm{ml}$ of test sample solution $(10-250 \mu \mathrm{g} / \mathrm{ml})$. The entire reaction assembly was enclosed in a box lined with aluminum foil. The test tubes were kept in front of a fluorescent light and absorbance was read at $560 \mathrm{~nm}$ after $20 \mathrm{~min}$. The percentage inhibition of superoxide generation was obtained by comparing the absorbance of the control and those of the reaction mixture containing test sample as per the equation:

$$
\begin{aligned}
& \% \text { inhibition }=\frac{A a-A s}{A o} \times 100 \\
& \text { Where } A_{0}=\text { absorbance of the control } \\
& A_{s}=\text { absorbance of the test sample }
\end{aligned}
$$

Triplicate values were taken. 


\section{In Vitro Nitric Oxide Radical (NO') Scavenging Assay}

Nitric oxide radical (NO) generated from sodium nitroprusside (SNP) was measured according to the method of Marcocciet al. (1994). Four different test tubes were set up.Test tube one $\left(\mathrm{T}_{1}\right)$ contained $8 \mathrm{ml}$ of sodium nitroprusside (SNP) mixture (5 $\mathrm{mM} \mathrm{SNP}$ in phosphate buffered saline (PBS) $\mathrm{pH}$ 7.3).

Test tube two $\left(\mathrm{T}_{2}\right)$ contained $4 \mathrm{ml}$ of extract $(500 \mu \mathrm{g} / \mathrm{ml})+4 \mathrm{ml}$ SNP in PBS.Test tube three $\left(\mathrm{T}_{3}\right)$ contained $4 \mathrm{ml}$ extract $(250 \mu \mathrm{g} / \mathrm{ml})+4 \mathrm{ml} \mathrm{SNP}$ in PBS andTest tube four $\left(\mathrm{T}_{4}\right)$ contained $4 \mathrm{ml}$ ascorbic acid standard $(500 \mu \mathrm{g} / \mathrm{ml})+4 \mathrm{ml} \mathrm{SNP}$ in PBS.The mixtures were incubated at $25^{\circ} \mathrm{C}$ for 180 minutes in front of a fluorescent tube. The NO radical generated in each test tube photochemically interacted with oxygen toproduce the nitrite ion $\left(\mathrm{NO}_{2}{ }^{-}\right)$which was assayed using a spectrophotometer at 30minintervals. The standard was sodium nitrite and the standard curve was generated thus:

Different concentrations of sodium nitrite $(7.78 \mu \mathrm{g} / \mathrm{ml}-100 \mu \mathrm{g} / \mathrm{ml})$ were put in tentest tubes.

This was followed by the addition of $1.0 \mathrm{ml}$ of Griess Reagent $(1 \%$ Sulfaninamide in $5 \%$ phosphoric acid and $0.1 \%$ naphthylethylenediaminedihydrochloride) toeach of the ten test tubes. The absorbance of the chromophore (purple azo dye) formed duringthe diazotization of nitrite ions with sulfanilamide and subsequent coupling withnaphthylethylenediaminedihydrochloride was measured at $546 \mathrm{~nm}$. The nitrite generated inthepresence of the plant extract was extrapolated from the standard curve plotted betweenabsorbance and their corresponding concentrations (nitrite ions generated from sodiumnitrite).

\section{Determination of Total Phenolic Contents}

The total phenolics were determined using the method of Veliogluet al., (1998).With slight modifications. $100 \mu \mathrm{l}$ of the extract $(1 \mathrm{mg} / \mathrm{ml})$ dissolved in ethanol, was mixed with $750 \mu 1$ of folin-Ciocalteau's Reagent (previously diluted 10-fold with distilled water) and

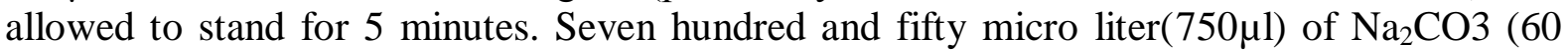
$\mathrm{g} / \mathrm{l})$ solution was then added to the mixture. The absorbance was readusing a JENWAY 6405 UV/VIS spectrophotometer (Beckman/Instruments, Inc., Huston Texas) at 725nm. Results were expressed as Gallic acid equivalents. Triplicate values were taken.

\section{Determination of Flavonoids}

One gram $(1 \mathrm{~g})$ of the extract was taken and macerated with $20 \mathrm{ml}$ of ethyl acetate for $10 \mathrm{~min}$. It was centrifuged for 5 minutes at $1000 \mathrm{rpm}$. Five milliliter $(5 \mathrm{ml})$ of the supernatant were each transferred into three test tubes into which $5 \mathrm{ml}$ of $1 \mathrm{M}$ ammonium hydroxide were poured and shaken vigorously for 2 to 5 minutes. The upper layers were discarded, and the absorbance of the lower layer wasreadusing a JENWAY 6405 UV/VIS spectrophotometer (Beckman/Instruments, Inc., Huston Texas) at 470nm. The blank was $1 \mathrm{~N}$ ammonia solution. Flavonoid calculation was done using standard curve. The standard curve was prepared in the same way the test sample was prepared. The absorbance of the standard was plotted against the concentration of the standard flavonoid. The flavonoid was quantified using the following:

$$
\begin{aligned}
& \frac{\text { Abs of Sample }}{\text { Slope (Standard) }} \mathrm{x} \text { dilution factor } \\
& \text { Triplicate values were taken. }
\end{aligned}
$$




\section{Determination of Tannin}

One gram $(1 \mathrm{~g})$ of the extract was macerated with $20 \mathrm{ml}$ of methanol for $10 \mathrm{~min}$. It was centrifuged for $5 \mathrm{~min}$ at $1000 \mathrm{rpm}$. The supernatant $(2 \mathrm{ml})$ were poured into three test tubes. Methanol, $(3 \mathrm{ml})$ were each poured into the test tubes followed by $0.3 \mathrm{ml}$ of $0.1 \mathrm{M}$ ferric chloride in $0.1 \mathrm{M} \mathrm{HCl}$ and then mixed thoroughly. To the mixture, was added $0.3 \mathrm{ml}$ of $0.0008 \mathrm{M}$ potassium ferricyanate, and mixed. The absorbance of the solutions in each of the tubes were read against the blankusing a JENWAY 6405 UV/VIS spectrophotometer (Beckman/Instruments, Inc., Huston Texas) at 750nm after $5 \mathrm{~min}$, but not exceeding $30 \mathrm{~min}$. The concentration of tannin was extrapolated from the standard curve (prepared as described earlier). Triplicate values were taken.

\section{Statistical Analysis}

Data were reported as means \pm SEM, where appropriate. One-way analysis of variance (ANOVA) and correlation analysis were used to analyze the experimental data and Duncan multiple test range was used to compare the group means obtained after each treatment with control measurements. Differences were considered significant when $\mathrm{P} \leq 0.05$.

\section{Results and Discussion}

Effect of Methanol Extract of Securidacalongepedunculata (MESL) on DPPH Radical Scavenging Activity

The quantitative DPPH analysis revealed DPPH radical scavenging activity of the plant part. The percentage inhibition was concentration dependent with an effective concentration at $50 \%\left(\mathrm{EC}_{50}\right)$ of $90.02 \pm 0.02 \mu \mathrm{g} / \mathrm{ml}$ compared to ascorbic acid standard with $\mathrm{EC}_{50}$ of $98.01 \pm 0.02 \mu \mathrm{g} / \mathrm{ml}$. (Table 1) The percentage inhibition against concentration showed a statistically strong significant positive correlation $(\mathrm{P} \leq 0.01)$, correlation coefficient $\left(\mathrm{R}^{2}\right)$ of 0.976. It, also, confirmed the ability of the extract to donate hydrogen atom to the stable free radical.The addition of the extract showed a progressive decrease in absorbance. DPPH is characterized as a stable free radical by virtue of the delocalization of the spare electron over the molecule as a whole, so that the molecules do not dimerize, like most other free radicals (Sagar and Singh, 2011).On mixing DPPH solution with a substance that can donate a hydrogen atom, it gives rise to the reduced form (Sagar and Singh, 2011). The odd electron of nitrogen atom in DPPH is reduced by receiving a hydrogen atom from antioxidants to the corresponding hydrazine (Rajesh and Natvar, 2011). Besides, cysteine, glutathione, ascorbic acid, tocopherol, poly-hydroxyl aromatic compounds reduce DPPH by their hydrogen donating ability (Blois, 1958). The extract has ascorbic acid (vitamin C) and protein ( cysteine might be one of amino acids that make up the sequence of the concerned protein found in the extract). These and other related compounds found in the extract might be responsible for the quenching of the DPPH radical.

Table1 Inhibition of DPPH radical by MESL

\begin{tabular}{lc} 
Concentration $(\mu \mathrm{g} / \mathrm{ml})$ & Percentage Inhib \\
\hline 9 & $83.17 \pm 0.00$ \\
19 & $84.62 \pm 0.01$ \\
30 & $85.58 \pm 0.00$ \\
42 & $90.22 \pm 0.00$ \\
54 & $91.03 \pm 0.01$ \\
68 & $93.59 \pm 0.00$ \\
83 & $94.23 \pm 0.00$
\end{tabular}


$\mathrm{EC}_{50}$ of extract $(\mu \mathrm{g} / \mathrm{ml})$ is $90.02 \pm 0.02$ compared to the standard

$\mathrm{EC}_{50}(\mu \mathrm{g} / \mathrm{ml})$ of ascorbic acid standard $(98.01 \pm 0.02)$

$\mathrm{n}=3$ (readings were determined at triplicates)

\section{Effect of MESL on Hydroxyl Radical (OH·) Scavenging Activity}

The extract showed scavenging activity against hydroxyl radical $\left(\mathrm{OH}^{\prime}\right)$ with an inverse relationship between the extract concentrations and \% inhibition. The percentage inhibition against concentration showed a statistically significant $(\mathrm{P} \leq 0.05)$ negative correlation with correlation coefficient $\left(\mathrm{R}^{2}\right)$ of -0.958 . The $\mathrm{EC}_{50}$ of the extract was $83.74 \pm 0.02(\mu \mathrm{g} / \mathrm{ml})$ as compared to $54.16 \pm 0.01(\mu \mathrm{g} / \mathrm{ml})$ of $\alpha$-tocopherol standard (Table 2$)$. Hydroxyl radical is a reactive oxygen species and it is a form of activated oxygen (Halliwell and Gutteridge, 1999). Its anti-radical power is 0.012 compared to 0.003 of superoxide. This suggested a stronger scavenging activity of the extract on hydroxyl radical compared to the extract's ability to scavenge superoxide radical. Hydroxyl radicals were generated using ascorbic acid-iron EDTA (Jayabalan, et al; 2007). Hydroxyl radical is an extremely reactive species formed in biological systems and has been implicated as highly damaging in free radical pathology, capable of damaging almost every molecule found in living cells (Hochestein and Attallah, 1988). This radical has the capacity to join nucleotides in DNA and cause strand breakage, which contributes to carcinogenesis, mutagenesis and cytotoxicity (Kappus, 1991). Hydroxyl radical is considered to be one of the quick initiators of lipid peroxidation process, abstracting hydrogen atoms from unsaturated fatty acids (Kappus, 1991). Polyphenolic compounds are known to have antioxidant activity and the activity of the extract in scavenging hydroxyl radical could be due to these polyphenolic compounds. This activity was believed to be mainly due to their redox properties which play an important role in adsorbing and neutralizing free radicals, quenching singlet and triplet oxygen or decomposing peroxides (Ali et al, 2010).

Table 2 Inhibition of OH'radical by MESL

Concentrations $(\mu \mathrm{g} / \mathrm{ml})$ Percentage Inhibition $(\%)^{\mathrm{n}}$

\begin{tabular}{lc}
\hline 5 & $90.24 \pm 0.00$ \\
10 & $85.37 \pm 0.00$ \\
25 & $65.00 \pm 0.01$ \\
50 & $63.41 \pm 0.01$ \\
125 & $34.15 \pm 0.02$ \\
$\mathrm{EC}_{50}(\mu \mathrm{g} / \mathrm{ml})$ & $83.74 \pm 0.02$ \\
\hline
\end{tabular}

$\mathrm{EC}_{50}(\mu \mathrm{g} / \mathrm{ml})$ of the extract is $83.74 \pm 0.02$ as compared to the standard

$\mathrm{EC}_{50}(\mu \mathrm{g} / \mathrm{ml})$ of $\alpha$-tocopherol (standard) $=54.16 \pm 0.01$

$\mathrm{n}=3$ (triplicates)

\section{Effect of the Extract(MESL) on Superoxide Radical Scavenging Activity}

There was a moderate superoxide radical scavenging. The percentage inhibition against concentration showed a statistically significant $(\mathrm{P} \leq 0.01)$ positive correlation with correlation coefficient $\left(\mathrm{R}^{2}\right)$ of 0.993 . The $\mathrm{EC}_{50}$ of the extract was $350.11 \pm 0.42(\mu \mathrm{g} / \mathrm{ml})$ while that of ascorbic acid standard was $812.97 \pm 0.97(\mu \mathrm{g} / \mathrm{ml})$ (Table 3). In cellular oxidation reactions, superoxide radicals are normally formed and their effects can be magnified because they produce other kinds of cell-damaging free-radicals and oxidizing agents. The extract inhibited the photochemical reduction of nitro blue tetrazolium (NBT) by superoxide in a 
concentration dependent manner as shown in Table 3. The decreases in absorbance at 560nm with antioxidants thus indicated the consumption of superoxide anion in the reaction mixture (Palashet al, 2009). The generation of superoxide radicals was reported to be inhibited by tannins (Chung et al, 1998). Tannins were contained in the extract. This further confirmed the antioxidant property of the extract, thereby making it an agent that could ameliorate the deleterious effect of free radicals (reactive oxygen species) which are sometimes generated in vivo(Nelson and Cox, 2005). The principal chain-breaking antioxidants, in vivo, are superoxide dismutase, which acts in the aqueous phase to trap superoxide free radicals $\left(\mathrm{O}_{2}^{-{ }^{-}}\right)$, urate and vitamin E, which act in the lipid phase to trap ROO radicals (Murray et al, 2006). The extract might, therefore, have a boosting effect on in vivo antioxidants.

Table 3Superoxide radical scavenging activity of the extract

\begin{tabular}{ll}
\hline Concentrations $(\mu \mathrm{g} / \mathrm{ml})$ & Percentage inhibition $(\%)^{\mathrm{n}}$ \\
\hline
\end{tabular}

$\begin{array}{lc}10 & 16.61 \pm 0.07 \\ 25 & 20.09 \pm 0.11 \\ 50 & 23.26 \pm 0.06 \\ 125 & 26.27 \pm 0.13 \\ 250 & 41.46 \pm 0.13\end{array}$

$\mathrm{EC}_{50}(\mu \mathrm{g} / \mathrm{ml})$ of extract is $350.11 \pm 0.42$ compared to the standard

$\mathrm{EC}_{50}(\mu \mathrm{g} / \mathrm{ml})$ of Ascorbic acid $($ Standard $)=812.97 \pm 0.97$

$\mathrm{n}=3$ (triplicates)

\section{Effect of MESL on Nitric Oxide Radical Scavenging Activity}

The extract, also showed nitric oxide radical scavenging activity (Fig.1). Scavengers of nitric oxide compete with oxygen, leading to reduced production of nitrite ions (Rajesh and Natvar, 2011).Securidacalongepedunculatahad higher scavenging activity at $500 \mu \mathrm{g} / \mathrm{ml}$. The fluctuating nature observed at different intervals, might be as a result of steady state complex formation which tend to proceed to form nitrite ion or dissociate to form nitric oxide. This is healthy in a system where nitric oxide serves like two- edged sword. It could be beneficial or deleterious. This equilibrium point can be drawn to favour nitric oxide's (NO) role in immune system integrity or to nitrite $\left(\mathrm{NO}_{2}{ }^{-}\right)$which indicated reduced production of nitrite ions. Thus, there is need for a moderate scavenging activity for nitric oxide. If this were not so, nitric oxide's role in immunity would be compromised. These different assays (DPPH, hydroxyl, superoxide and nitric oxide radicals) are needed to confirm the scavenging activity of a given extract since the antioxidant activity measured depends substantially on the test system used (Janaszewska and Bartosz, 2002). Therefore it is recommended that conclusion should be based on at least two different systems (Moon and Shinamoto, 2009). 


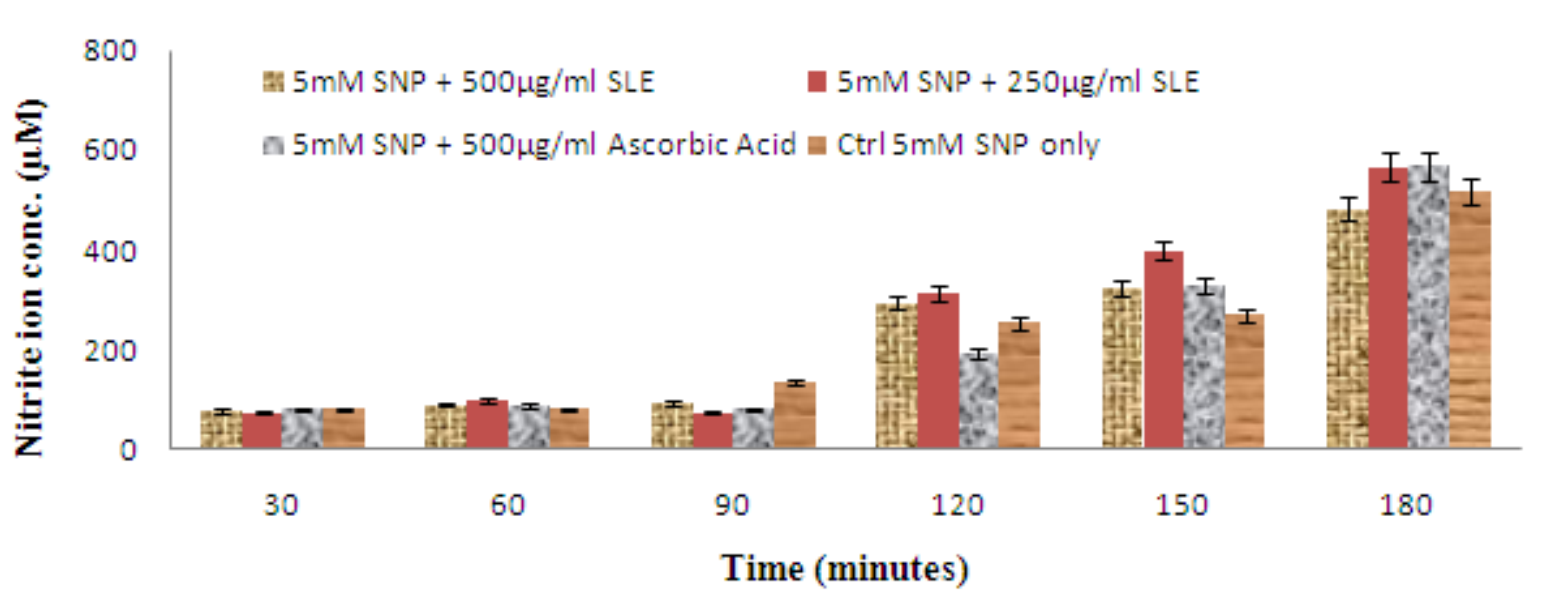

Fig.1 nitric oxide radical scavenging activity of MESL

\section{Comparison of the Anti Radical Power of the Extract against DPPH' Superoxide Radical and Hydroxyl Radical Scavenging Activity}

Anti Radical Power (ARP) is the inverse of the effective concentration of extract that can scavenge $50 \%$ of the oxidant $\left(\mathrm{EC}_{50}\right)$. It shows the strength of the extract in quenching the oxidants (NO, OH, $\mathrm{O}_{2}$ among others). The higher the ARP the more powerful the extract was in quenching the radical with respect to the method used. In this study, the ARP against Hydroxyl radical was the highest, showing that the extract had the ability to quench hydroxyl radical more than the other radicals compared (Fig. 2).

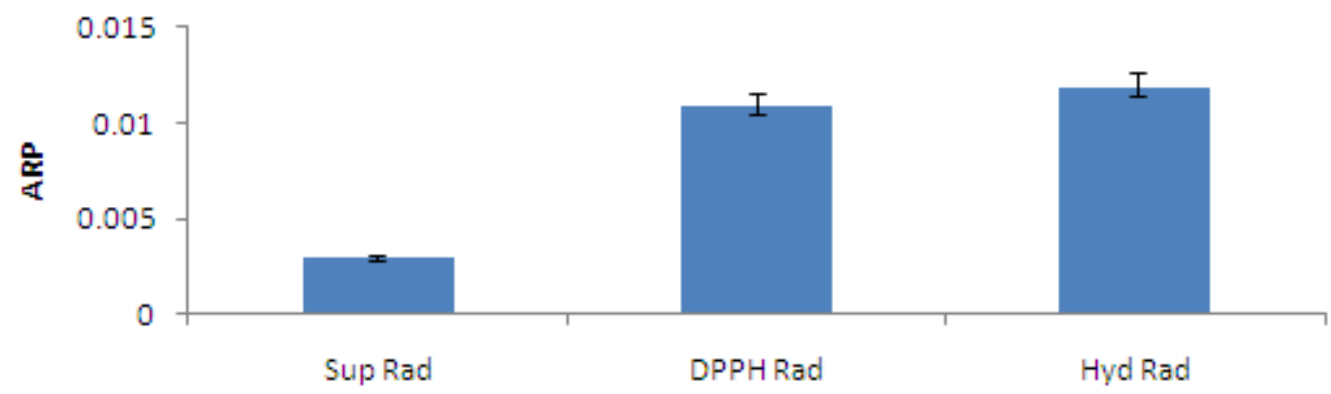

Fig.2Different anti radical power (ARP) of the extract against the different free radicals used.

\section{Conclusion}

The antioxidant property of Securidacalongepedunculata points to its relevance in ameliorating different deleterious effects associated with reactive oxygen species. However, there is a need to study extensively the in vivo antioxidant effect so as to ascertain whether what happened in vitro would be duplicated in vivos notwithstanding the moderate antioxidant effect is healthy as it would allow the system to use its free radical arsenal as well as moderate the adverse effects of over generation of free radicals.

\section{References}

[1]. Abdullahi, S.K. and Lawal, G.H.(2010).Antibacterial Screening and Brine Shrimp (Artemia salina)Toxicity of Securidacalongepedunculata (Polygalaceae) Root Bark. African Journal ofPharmaceutical Sciences, 1:85- 95.

[2]. Ajiboye, T.O., Salau, A.K., Yakubu, M.T.,Oladiji,A.T., Akanji,M.A. and Okokun J.I.(2010.). Imbalance in Male Rat Liver and Kidney. Human and Experimental Toxicology, 29(8):679-688. 
[3]. Akinniyi, J.A., Manawadu, D. and Sultanbawa, M.(1996).Ethnobotany and Ethnopharmacology ofNigerian Medicinal Plants Research Traditional Medicine in Malaria.

[4]. Ali, G., Hawa, Z. E. J. and Asmah, R. (2010). Antioxidant activities, total phenolics and flavonoidscontent in two varieties of Malaysia young ginger (Zingiberofficinale Roscoe). Molecules, 15:4324-4333.

[5]. Astley, S.B. (2003). Dietary antioxidants past, present and future. Trends Food Sci Technology14: 93-98.

[6]. Atoui, A.K., Mansouri, A. Boskou, G. and Kefalas, P. (2005). Tea and herbal infusions their antioxidant activity and phenolic profile. Food Chemistry, 89: 27-36.

[7]. Balasundram, N.,Sundram, K and Samman, S. (2006) Phenolic compound in plants and agric-industrial by-products, Antioxidant activity, occurrence and potential uses. Food Chemistry, 99: 191203

[8]. Blois, M. S. (1958). Antioxidant determination by the use of stable free radicals. Nature, 181: $\quad 1199-2000$.

[9]. Chung, K.T., Wong, T.Y., Wei, C.I., Huang, Y.W. and Lin, Y. (1998). Tannins and human health:a review. Review of Food Science and Nutrition, 38 (6): 421-464.

[10]. Gill, L. S. (1992). Ethnomedical uses of plants in Nigeria. Uniben Press Benin City Nigeria.

[11]. Gulcin, I. and Oktay, M.O. (2002). Determination of antioxidant activity of lichen Cetraria islandica (L). Ach. Journal of Ethnopharmacology, 79: 325-329.

[12]. Gulcin, I., Sat, I.G., Beydemir, S., Elmastas, M. and Kufrevioglu, O. I. (2004). Comparison ofantioxidant activity of clove (Eugenia caryophylataThunb) buds and lavender (Lavandulastoechas L.). Food Chemistry, 87: 393-400.

[13]. Halliwell, B. and Gutteridge, J.M.C. (1989). Free radicals in Biology and Medicine. $2^{\text {nd }}$ Edn Clavendon Press. Oxford UK.

[14]. Halliwell, B. and Gutteridge, J.M.C. (1999). Free radicals, other reactive species and disease.

[15]. In:Free radical in Biology and Medicine. Clarenden Press, Oxford, Pp: 617783.

[16]. Halliwell, B (2007). Oxidative stress and cancer: have we moved forward? Biochemical Journal, 401(1): 1-11.

[17]. Hras, A. R., Hadolin, M., Kenez, and Bauman, O. (2000). Comparison of antioxidative and synergistic effects of rosemary extract with alpha-tocopherol, ascorbylpalmitate and citricacid in sunflower oil. Food Chemistry, 71: 229-233.

[18]. Iddagoda, L. and Thamara, K.J.D.(2003).Phytochemical studies of Securidaca longepedunculata andits use as a deterrent against stored grain insect pests. A Thesis

Submitted in Fulfilment of theRequirement of the University of Greenwich for theDegree of Doctor of Philosophy.

[19]. Janaszewska, A. and Bartosz, G. (2002). Assay of total antioxidant capacity: Comparison of four methods as applied to human blood. Scandinavian Journal of Clinical Laboratory Investigations. 62: 231-236.

[20]. Jayabalan, R., Marimuthu, S. and Swaminathan, K. (2007). Changes in content of organic acidsand tea polyphenols during Kombucha tea fermentation. Food Chemistry, 102: $\quad 392-398$.

[21]. Kahkonen, M.P., Hopia, A.I. Vuorela, H.J., Rauha, J.P., Pihlaja, K., Kujala, T.S. and Heinonen, M.(1999). Antioxidant activity of plant extracts containing phenolic compounds.Journal of Agriculture and Food Chemistry, 47(10): 3954-3962. 
[22]. Kappus, H. (1991). Lipid peroxidation-mechanism and biological relevance. In Aruoma, O. I. and Halliwell, B. (Eds), Free radicals and food additives. Taylor and Francis, London. Pp. 59-75.

[23]. Kourounakis, A.P. and Galanakis, D.K. (1999). Synthesis and Pharmacological evaluation of novelderivatives of anti-inflammatory drugs with increased antioxidant and anti inflammatoryactivities. Drug development Research, 47:9-16.

[24]. Mohammed, A., Ndamitso, M. M. and Aisha, R.S. (2012.).Phytochemical and, Antibacterial activityofSecuridacalongepedunculata on selected pathogens. Prime Research on Medicine,2(3):89-934.

[25]. Moon, J. K. and Shinamoto, T. (2009). Antioxidant assays for plant and food components. Journal of Agricultural Chemistry. 57:1655-1666.

[26]. Murray, R. K., Granner, D. K. and Rodwell, V. W. (2006). Harper's Illustrated Biochemistry. $27^{\text {th }}$ ed.McGrawHill . New York. P. 129.

[27]. Nelson, D.L. and Cox, M.M. (2005). Lehninger Principle of Biochemistry. $4^{\text {th }}$ ed. McGraw Hill. New York. P. 873.

[28]. Ojewole, J. A. O. (2008). Analgesic, anti-inflammatory and hypoglycaemic effects of SecuridacalongepedunculataFrasen (Polygalaceae) root bark aqueous extract. Inflammapharmacology, 15: 174-181

[29]. Owoyele, B.V., Iranloye,B.O., Ayeni, O.J. and Soladoye, A.O.(2006). Effects of methanolic extractsofSecuridacalongepedunculata leaves on the haematologic parameters and some serumelectrolytes in wistar rats. Chronic and Common Diseases, 11 (18): 3.

[30]. Palash, M., Tarun, K. M. and Mitali, G. (2009). Free radical scavenging activity and phytochemicalanalysis in the leaf and stem of DrymariadiandraBlume. InternationalJournal of Integrative Biology, 7 (2) 80.

[31]. Psotova, J., Zahalkova,J. Hrbrac, J., Simanek, V. S. and Bartek, J. (2001). Determination of total antioxidant capacity in plasma by cyclic voltameter. Two case reports Biomedical Papers, 145 (2): 81-83.

[32]. Rajesh, P.M. and Natvar, P.J. (2011). In vitro antioxidant activity of coumarin compounds by DPPH,Superoxide and Nitric oxide free radical scavenging methods. Journal of Advanced PharmacyEducation and Research, 1:52-68.

[33]. Sagar, B.K. and Singh, R.P. (2011). Genesis and development of DPPH method of antioxidant assay. Journal of Food Science and Technology, 48(4): 412-422.

[34]. Yildrin, A. and Mavi, A. (2000). Comparison of antioxidant and antimicrobial activities of tilia(TiliaargentaDesf Ex DC), saga (Salvia tribola L.) and black tea (Camelia sinensis)extracts. Journal of Agricultural and Food Chemistry, 48: 5030-5034. 